\title{
A cross-cultural comparison of organisational commitment amongst vehicle sales staff
}

\author{
C.F. Magano and A. Thomas* \\ Department of Business Management, University of Johannesburg, \\ PO Box 524, Aukland Park 2006, Republic of South Africa \\ adelet@uj.ac.za \\ G.P. de Bruin \\ Department of Industrial Psychology and People Management. \\ University of Johannesburg
}

Received January 2010

\begin{abstract}
The automotive industry is regarded as being critical to the economic growth of South Africa (Horn, 2007). As the achievement of organisational goals occurs largely through the performance of committed human resources (Nijhof, De Jong \& Beukhof, 1998), the purpose of the present study was to gain a deeper understanding of the differences in organisational commitment amongst different language groups (language being a proxy of culture) of vehicle sales staff at a large South African motor retailer.
\end{abstract}

The unit of analysis for the study was individual employees $(n=314)$ and the data were collected through the administration of the TCM survey questionnaire developed by Allen and Meyer (1990) to measure affective, normative and continuance commitment. The majority of respondents $(36,90 \%)$ were African language speakers, $32,30 \%$ were English language speakers and 3,60\% were Afrikaans language speakers.

Results indicate that African language respondents scored significantly lower on normative commitment than did either the Afrikaans or English respondents. No significant differences in normative commitment were observed between the Afrikaans and English respondents.

Given the strategic importance of the automotive industry to the South African economy, this finding could alert managers to the necessity of understanding the reasons for the lower normative commitment of the African language group (compared to the Afrikaans and English speakers) and, accordingly, to devise ways of increasing normative commitment with this group.

*To whom all correspondence should be addressed.

\section{Introduction}

Successful organisations strive to attract, recruit, engage and retain people who are competent and able to display effort, motivation and initiative to drive the organisation to higher levels of performance and to deliver shareholder value (Batra, 1996; Nijhof, De Jong \& Beukhof, 1998). The willingness of employees to exert effort to contribute value in the organisation is accomplished within the context of their experience of the culture that characterises the organisation and its environment (Naudé, Desai \& Murphy, 2003).

There is increasing recognition of the limitations of traditional organisational theories and management approaches that assume individual and cultural homogeneity in the workplace (Tjovsvold \& Leung, 2003). Expanding international trade and continued immigration flow demands that people of diverse cultures work together (Du Plessis, 2007; Tjovsvold \& Leung, 2003). Equally, with the promulgation of the Employment Equity Act No 55 of 1998 (Republic of South Africa, 1998) and other legislative changes, the South African workplace is increasingly incorporating people from diverse backgrounds and cultures whose commitment to the organisation must be secured (Du Plessis, 2007; Nel \& Du Plessis, 2007). Such organisational commitment can be described as a set of behaviours or attitudes that manifest as attachment, involvement, identification and loyalty of employees (Alatrista \& Arrowsmith, 2004). However, the challenge for South African managers in securing commitment from employees is often compounded by "workplaces characterised by adversarial relationships, lack of trust and communication between individuals and groups, poor team work and high staff turnover, especially from designated groups" (Thomas, 2002:239).

Whether employees from diverse backgrounds differ with respect to organisational commitment represents a potentially important theoretical and practical problem. This 
study contributes to the understanding of this problem by examining differences in organisational commitment of employees from diverse language (and by implication cultural) backgrounds in a division of a South African automotive company. In exploring this problem, management in the automotive industry stands to gain a better understanding of organisational commitment amongst such diverse groups, particularly as such commitment could impact service, critical to sales in this industry (Berndt \& Herbst, 2006). This understanding could inform strategies to motivate and retain a diverse employee body to promote the sentiments of the Employment Equity Act (Republic of South Africa, 1998) and, simultaneously, to address challenges related to promoting the competitiveness of the industry.

\section{Context of the present study}

The present study focuses on a South African motor vehicle retail group that employs some 7800 people, with 887 being vehicle sales staff, in franchised motor dealerships. The company has experienced increased competition in recent years with the entrance of new competitors from Korea and China, compounding already existing economic, political and socio-cultural challenges in the business environment. The impact has been felt across a range of areas in the business including management and leadership effectiveness and performance, customer service delivery, retention of key skilled staff, recognition and compensation of staff and high labour turnover, in particular, amongst vehicle sales staff (Pretorius, 2006), with vehicle sales staff from different cultural groups appearing to differ with respect to their levels of organisational commitment.

The automotive industry in South Africa is one of the most significant contributors to the country's economic growth, with a contribution of $6,6 \%$ towards GDP, accounting for $30 \%$ of manufacturing output and directly employing approximately 297,000 people (Horn, 2007). This industry is important to the success of the South African economy and employee commitment can be expected to play a crucial role in ensuring efficiencies as noted in research that links organisational commitment to organisational success (cf. De Chertony \& Segal-Horn, 2003; Jackson, 2004; Lytle \& Timmerman, 2006; Rashid, Sambasivan \& Johari, 2003).

A further contextual factor to the present study is the multilingual and multicultural composition of the South African workplace. Culture and language are intimately linked (cf. McClean, 2000). Indeed, writing within the South African context, Rudwick (2008: 108) notes that the "loss of the mother tongue is frequently perceived as a cultural loss as well". However, because of educational and other acculturation processes, language is not a flawless proxy for culture in the South African context (cf. Bangeni \& Kapp, 2007). Still, it is reasonable to assume that a person's home language may be broadly reflective of his or her cultural background.

In the South African context, language and race were historically linked to different experiences with respect to education and work. White Afrikaans and English-speaking conglomerates have predominantly controlled the economy, while the workforce has been, and currently is, primarily comprised of black indigenous language speakers. Generally, western cultures (and by implication white Afrikaans and English first language speakers) emphasise individualism and independence, whereas African cultures (and by implication black indigenous African first language speakers) emphasise collectivism and interdependence (cf. Lessem, Christie \& Mbigi, 1993; Markus \& Kitayama, 1991; Triandis, 2001; Mbigi, 1997). Thomas and Ely (1996) note that the decisions and choices that employees make are often based upon their cultural backgrounds. Cultural background may also directly impact commitment in the workplace (Kamenou \& Fearfull, 2006).

\section{Literature review}

\section{Organisational commitment}

Commitment is a force that binds employees to courses of action relevant to one or more targets e.g. organisation, work-team, occupation/career (Meyer \& Herscovitch, 2001). Such commitment can influence behaviour even in the absence of extrinsic motivation or positive attitude. The success of an organisation depends not only on how the organisation makes the most use of its human resources but also how it stimulates organisational commitment (Nijhof et al., 1998). Alatrista and Arrowsmith (2004: 537) note organisational commitment to be "the extent to which employees identify with the goals of the organisation or ... the process by which people come to think about their relationship with the organisation ... a mind-set in which individuals consider the extent to which their own values and goals are congruent with those of the organisation".

Mowday, Steers and Porter (1979) note organisational commitment to be a global construct that reflects an employee's affective response to the antecedents and conditions of the whole organisation rather than to the narrower aspects of the organisation such as job, work-team or occupation. In this regard, these authors view organisational commitment as being more stable than, for example, job commitment that may change on a day to day basis. According to Tam, Korczynski and Frenkel (2002), one of the important issues in management-employee relationships is determining the locus of employee commitment in the organisation. Different individuals may be highly committed to their teams, occupations or careers but not to the organisation, or may be committed to both the team and career or committed to neither (Bishop, 1997; Meyer \& Herscovitch, 2001). Mowday et al. (1979) further suggest that organisational commitment develops over time as the employee's relationship with the organisation matures, aided by a perception of congruence and mutuality between employee and organisational goals.

Labatmedienè, Endriulaitienè and Gustainienė (2007: 197) note that organisational commitment reflects "the strong belief in and acceptance of the organizational goals and values, a willingness to exert considerable effort on behalf of the organization and the desire to remain in the organization". Mowday et al. (1979) and Labatmedienè et al. (2007) suggest that organisational commitment can be judged by an employee's favourable course of action on 
behalf of the organisation (behavioural manifestation) and by the expression of positive opinions and beliefs by employees about the organisation (attitudinal manifestation). Nijhof et al. (1998) conclude that organisational commitment leads to positive effects for the company such as improved quality, better client relationships, better communication, less illness, greater commitment to change, positive commitment to actively participating in change processes and increased innovation to resolve work related problems.

Organisations often invest scarce resources to attract, recruit and engage new employees, train and develop them, create career prospects but fail to secure organisational commitment, resulting in high employee turnover (Kazlauskaite, Buciuniene \& Turauskas, 2006). Bishop (1997) notes how building organisational commitment in the workplace is a critical goal of human resource management policies and practices, impacting positively on productivity, lowering employee turnover and promoting employee willingness to help co-workers while Rudman (2008) believes that developing such commitment is a shared responsibility between line management and the human resource function.

\section{Unitary and pluralist organisational commitment}

\section{definitions}

of

The unitary view of organisational commitment is based on the premise that the construct of organisational commitment can be measured independently as a set of behaviours or attitudes, manifesting in the form of attachment, involvement, identification and loyalty of an employee in a particular organisation (Alatrista \& Arrowsmith, 2004). When defined in this fashion, organisational commitment "represents something beyond mere passive loyalty to an organization; it involves an active relationship with the organization such that individuals are willing to give something of themselves in order to contribute to the organization's well-being" (Mowday et al., 1979: 226).

On the other hand, a pluralist view considers organisational commitment as a construct that correlates with other constructs such as personal, job and organisational characteristics (Alatrista \& Arrowsmith, 2004). In this regard, the personal characteristics that are frequently studied are age and levels of education. The characteristics that are frequently associated with organisational commitment at job level are: interest in the job, task variety, feedback on tasks, mental load, work pressure and reward systems (Williamson, Burnett \& Bartol, 2009). At an organisational level, characteristics such as number of employees, the extent of participative leadership, career prospects, possibilities for further education, on-going learning, self-leadership behaviour and style of leadership are some of the factors that have been associated with organisational commitment (Song \& Kim, 2009).

\section{A theoretical framework of organisational commitment}

The present study is predicated on the theoretical framework of organisational commitment developed by Allen and Meyer (1990) and Meyer and Allen (1991) who identify a three-component conceptualisation of organisational commitment, namely affective commitment, continuance commitment, and normative commitment. Affective commitment refers to an employee's positive emotional attachment to, identification with and involvement in the organisation (manifested in a desire to be in the organisation); continuance commitment refers to commitment based on the perceived cost that the employee associates with leaving the organisation (manifested in the employee weighing up of the cost of leaving the organisation); and normative commitment which refers to an employee's feelings of obligation to remain with the organisation. Martin (2008) summarises the above components of commitment by noting that employees evidencing strong affective commitment stay with the organisation because they "want to"; those demonstrating strong continuance commitment stay because they "need to" and those with strong normative commitment, stay because they "ought to".

Affective commitment, continuance commitment and normative commitment (Allen \& Meyer, 1990) have been shown to be associated with constructs such as personal factors (age and level of education), job factors (variety in task, feedback of task results, mental load and work pressure) (Nijhof et al.,1998); and organisational factors (job satisfaction, absenteeism, and employee turnover) (Bishop, 1997). Moorman, Niehoff and Organ (1993) found affective commitment to be linked to extra-role behaviours; Gellatly (1995) notes a link between affective commitment and absenteeism and Mathieu and Zajac (1990) and Somers (1995) found affective commitment to be associated with employee turnover. Martin (2008) reports that affective commitment is determined by the interaction between the organisation and its employees and also demonstrates a link between affective commitment and normative commitment, such that lowered affective commitment is associated with lowered normative commitment.

Meyer and Herscovitch (2001) conclude that the affective, continuance and normative commitment components of mind-sets can be measured and that an employee commitment profile can be established, noting that these mind-set components have consistently been statistically validated. Lee, Allen, Meyer and Rhee (2001) note that the three commitment constructs, taken together, appear to be conceptually and functionally similar, and therefore generalisable across cultures. However, these authors note that there is possibly a need to refine these measures for cross-cultural research.

\section{Cultural diversity in the workplace}

Appelbaum, Shapiro and Elbaz (1998), Bhadury, Mighty and Damar (2000) and Robbins and Judge (2007) note how 
global interdependence and free trade agreements have promoted increasing cultural diversity in the workplace and Evans (2006) states that mergers, acquisitions, international joint ventures and strategic alliances, all strategies that bring diverse employees together, are the most frequently used forms of market entry. According to Tjosvold and Leung (2003), the ability to live and work across boundaries will influence the success of organisations in the future. Higgs (1996) proposes that organisations that intend working across national boundaries are faced with the challenge of building practices that promote global competitiveness, multinational flexibility and learning capacity along with a capacity to develop cultural sensitivity in order to use the synergistic contributions of diverse employees for strategic advantage. Such cultural diversity can include multiple dimensions relating to demographic and social similarities and differences among people (Cox \& Blake, 1991). It can be expected that the varying cultural diversity of employees will influence their ways of approaching problems and problem solving and, in general, contribute to the competitiveness that such diversity affords business (Bassett-Jones \& Lloyd, 2005; Richard, 2000).

Fontaine (2007) argues that cultural values are fixed and cannot be changed whereas contextual factors can be managed, leading to change in employee behaviour. $\mathrm{Ng}$ and Burke (2004) propose that cultural values are the unconscious and non-verbal, deepest sentiments which represent the attitudes of the majority of people in a specific cultural group, while Tjosvold and Leung (2003:4) define cultural values as "stable long-term beliefs that can be measured and compared, not induced" and state that they affect the outlook, approach and effectiveness of individuals in the workplace.

Tan, Härtel, Panipucci and Strybosch (2005:4) note how cultural identity provides people with a sense of community because it "encompasses an evolving set of shared beliefs, values, attitudes and logical processes that provide cognitive maps that people within given societal groups use to perceive, think, reason, act, react and interact". Peppas and $\mathrm{Yu}$ (2007) propose that there is a greater likelihood that values of members of homogeneous groups will coincide, but that due to the diverse nature of the local and global workplaces, employees increasingly interact with others possessing value systems different from their own which does not always result in successful collaboration. Added to this, Peppas and $\mathrm{Yu}$ (2007) propose that the distance between employees of different cultures is greater where historical segregation of peoples from different cultures has precluded the blending of values, an observation that is pertinent within the South African workplace.

Kanter and Corn (1994) suggest there has been an increasing focus on management problems caused by national cultural differences as organisations embark on cross-border relationships. Seymen (2006) states that employees of different cultures often experience difficulty in understanding the similarities and differences between one another, a difficulty that Demer (2002) notes to contribute to economic loss in South Africa. Accordingly, local and multinational organisations are grappling with the dual challenges of developing cultural sensitivity and the ability to build future organisational capabilities (Demer, 2002; Higgs, 1996). In South Africa, workplace diversity challenges are compounded by historical practices of workplace discrimination and segregation against the contextual background of the relationship between community and workplace (Miller, Haskell \& Thatcher, 2002).

\section{Cultural diversity and organisational commitment}

Mellahi (2001) and Jackson (2002) advocate that different cultures manifest different values and approaches to humanity, a sentiment that echoes in the seminal works of Hofstede (2001) and the more recent GLOBE study (House, Hanges, Javidan, Dorfman \& Gupta, 2004).

Fontaine (2007) believes that contextual factors such as national policies and organisational or individual factors are more important in explaining variation in work values among employees than their cultural values as contextual factors interact with and influence cultural values. However, according to Tan et al. (2005), the inherent differences between the underlying values and beliefs of different cultural groups will impact the attitudes of employees towards organisational commitment experiences.

Williamson et al. (2009) note that employees from different cultural backgrounds may evaluate the same workplace differently and they have demonstrated the interactive effect of employee culture and workplace rewards on the development of organisational commitment. $\mathrm{Ng}$ and Burke (2004) note that race accounts for significant variance in cultural values that may be linked to organisational commitment. Jackson (2002) proposes that, in the workplace, where people of different cultures encounter incompatibilities between their value systems and traditions, lack of motivation and alienation leading to low productivity and labour strife can be expected. Such behaviour may be a manifestation of poor work commitment (Rupert, Jehn, Van Engen \& De Reuver, 2010). In this vein, Naudé et al. (2003) state that employees who share similar values to those of the organisation, who have positive attitudes towards the organisation and who identify strongly with the organisation may be expected to show high levels of organisational commitment and low propensities to leave. With regard to people who are demographically dissimilar to the majority of other members of the organisation, Riordan and Shore (1997) and Chattopadhyay (1999) suggest that such employees will evidence reduced feelings of commitment to the organisation.

Rupert et al. (2010) suggest that cultural dissimilarity impacts attitudes, performance and organisational commitment. In this vein, Thomas (2003) suggests that problems relating to the retention of black employees are evident where appointments are based on demographic status as opposed to being based upon skills or qualifications. Kirby and Richard (2000) believe that such practices contribute to less psychological commitment to the organisation amongst those who are the subjects of such practices. 
It cannot be assumed that organisational commitment would retain its exact psychological or managerial importance in the South African context when the construct and its operationalisation were developed in a Eurocentric context (cf. Van de Vijver \& Leung, 1997). In addition, it should also not be assumed that organisational commitment has the same psychological and managerial importance amongst different cultural groups within South Africa. Rather, empirically examining similarities and differences in the manifestation of organisational commitment amongst different cultural groups is needed in the South African context to allow for a better understanding of the generality of the construct and its application.

\section{Issues in cross-cultural research}

Methodological considerations in conducting cross-cultural research often centre on the interpretation of observed cultural differences and the reduction of the number of alternative explanations for these differences. Erwee, Lynch, Millett, Smith \& Roodt (2001:7) note that contextual differences can produce differences in meaning whereby a respondent from one context regards the question as having one meaning while a respondent from another context attributes a different meaning to the same question.

One way in which the equivalence of meaning of a construct across groups can be established is by conducting separate factor analyses of the variables in the different groups and to then compare the factors by means of a coefficient of congruence (cf. Van de Vijver \& Tanzer, 2004). According to MacCallum, Widaman, Zhang and Hong (1999), high values of the coefficient of congruence are indicative of close correspondence between factors across the different groups (the coefficient of congruence ranges from zero to one). MacCallum et al. (1999) suggest a rule of thumb whereby good matching of factors is indicated by a congruence coefficient of 0.90 or greater. They also provide the following qualitative guidelines for interpreting coefficients of congruence: 0,98 to $1.00=$ excellent; 0,92 to 0,98 = good; 0,82 to $0,92=$ borderline; 0,68 to $0,82=$ poor and below 0,68 = terrible (MacCallum et al., 1999).

An additional step in examining construct equivalence across groups is to compare the correlations of the variables of interest across the different groups. Differences in the correlation of two variables across groups might indicate differences in the psychological meaning of the constructs represented by the variables across the groups. If no such differences are observed, and the factor structures of the variables are the same across groups, it may be considered safe to proceed to the comparison of mean scores across groups (cf. Van de Vijver \& Leung, 1997).

Equivalence also needs to be established on the item level if a questionnaire is to be fairly used across different groups. To this end, items that display differential functioning (DIF) across groups are identified. An item is said to function equivalently across groups if two individuals who belong to different groups, but have the same standing on the attribute of interest, have the same predicted score on the item. By contrast, an item is said to function differently across groups if two individuals who belong to different groups, but have the same standing on the attribute of interest, have different predicted scores on the item (Van de Vijver \& Tanzer, 2004). In practical terms, the safe use of a measure of organisational commitment across different language groups would mean that individuals with the same levels of organisational commitment should respond similarly to the items of the questionnaire, regardless of the language group to which they belong.

\section{Statement of hypothesis}

The principal objective of the present study was to examine whether components of organisational commitment differ significantly across language groups amongst vehicle sales staff within a South African automotive company. The sub objectives of the present study were: (a) to examine the construct equivalence of organisational commitment across language groups by means of factor analysis and by comparison of scale correlations across groups; and (b) to compare across language groups mean scores for affective commitment, continuance commitment and normative commitment. With respect to the second objective, the following hypothesis is formulated:

Ho: There is no significant difference between the mean scores of different language groups of vehicle sales staff in respect of affective commitment, continuance commitment, and normative commitment.

Ha: There is a significant difference between the mean scores of different language groups of vehicle sales staff in respect of affective commitment, continuance commitment, and normative commitment.

\section{Research methodology}

The methodology employed was quantitative in nature and a survey developed by Allen and Meyer (1990) was used to collect the data from sample members. This method was appropriate for gaining information to answer the overall research question and against which the hypothesis could be tested.

\section{Participants}

All 887 vehicle sales staff of a prominent vehicle retailer in South Africa were included in the study. A response rate of $35,3 \%$ (314 employees) was achieved. The majority of the respondents were male $(76,3 \%)$. The single largest group of respondents comprised African language speakers (36,9\%); $32,3 \%$ were English language speakers and 30,6\% were Afrikaans language speakers. With respect to race $^{1}$ the majority of respondents were white $(58,7 \%), 37,0 \%$ were

\footnotetext{
${ }^{1}$ The racial categories are in accordance with those used in the Employment Equity Act (Republic of South Africa, 1998). Indian and coloured respondents might be expected to have English (Indian and coloured) or Afrikaans (coloured) as their first language. However, as the number of these respondents was small, it is not believed that this had a substantive impact on the present findings.
} 
African, 4,2\% were Indian and 2,2\% were coloured. The average age was 34,8 years with a standard deviation of 9,27 years. The single largest group of respondents $(31,0 \%)$ had worked for the organisation between one and two years; $27,7 \%$ had been employed at the organisation less than one year; $23,0 \%$ for more than four years, and 18,2\% between three and four years.

\section{Instrument}

The questionnaire used in the present study (with permission) was the TCM Employee Commitment Survey (hereafter referred to as the TCM Survey) developed by Allen and Meyer (1990) which includes items pertaining to employees' perceptions of their relationship with the organisation and their reasons for staying. Section One gathers demographic information. Section Two contains the 24 item employee commitment scale based on the threecomponent model of commitment developed by Allen and Meyer (1990), grouped according to the sub-scales: Affective Commitment Scale (ACS), Normative Commitment Scale (NCS) and Continuance Commitment Scale (CCS) and where responses are rated on a seven-point Likert scale. The questionnaire also includes reverse-keyed items. According to Shepherd and Mathews (2000:558), this scale is one of the most popular instruments used to measure organisational commitment. Labatmedienè et al. (2007) report reliabilities ranging from 0,62 to 0,85 for the subscales of the TCM Survey and, similarly, Stallworth $(2003 ; 2004)$ reports reliabilities ranging from 0,75 to 0,84 . Overall, this suggest that the questionnaire yields scores with sufficient reliability for research purposes.

\section{Procedure}

The TCM Survey was distributed by regional human resources managers to vehicle sales staff in individual business units/dealerships during 2009. Respondents were requested to anonymously and voluntarily complete the questionnaire and to return the completed forms to designated ballot boxes. Respondent anonymity was guaranteed.

\section{Data analysis}

The statistical analysis of data were undertaken with SPSS 15,0 for Windows. Separate factor analyses were performed across the different language groups of and for the pooled group. The coefficient of congruence was used as an agreement or equivalence index to estimate the construct equivalence of organisational commitment among different language groups (Welkenhuysen-Gybels \& Van de Vijver, 2001). The equivalence of the correlations between the three subscales across the three groups were examined by means of Paul's (1989) test for the equivalence of independent correlations across three or more groups. Items were examined for the presence of DIF by means of the conditional ANOVA procedure described by Van de Vijver and Leung (1997). In this procedure item score serve as the dependent variable, whereas group membership and trait or attribute level serve as the independent variables. A significant effect for the interaction of trait level and group membership indicates non-uniform DIF (i.e. the item is differentially related to the trait of interest across groups), whereas a significant effect for language group indicates uniform DIF (i.e. that the item is differentially more easy or difficult to endorse across groups). Because many different tests are performed across the 24 items, the criterion for statistical significance was set at the relatively stringent level of $\alpha=0,01$. In addition, no DIF effect was deemed as being practically significant if it accounted for less than $6 \%$ of the variance of the item.

To compare levels of organisational commitment across groups, multivariate analysis of variance (MANOVA) of the subscale and total scores for the TCM Survey were applied where language group served as the independent variable. A significant MANOVA was followed up by univariate ANOVAs and Tukey's post hoc test of Honestly Significant Differences (HSD).

\section{Results}

\section{Measures of central tendency and variability}

Table 1 contains a summary of the means and standard deviations of the TCM Survey and its components for the African language, English language and Afrikaans language groups. 
Table 1: Means and standard deviations for the three subscales and overall organisation commitment scale across language groups

\begin{tabular}{|c|c|c|c|c|c|}
\hline Language group & Statistic & $\begin{array}{c}\text { Affective } \\
\text { commitment }\end{array}$ & $\begin{array}{l}\text { Continuance } \\
\text { commitment }\end{array}$ & $\begin{array}{c}\text { Normative } \\
\text { commitment }\end{array}$ & $\begin{array}{c}\text { Organisational } \\
\text { commitment }\end{array}$ \\
\hline \multirow[t]{3}{*}{ African } & Mean & 5,15 & 4,58 & 4,73 & 4,82 \\
\hline & $\mathrm{N}$ & 116 & 116 & 116 & 116 \\
\hline & SD & 1,15 & 1,13 & 0,99 & 0,86 \\
\hline \multirow[t]{3}{*}{ English } & Mean & 5,38 & 4,84 & 5,24 & 5,15 \\
\hline & $\mathrm{N}$ & 102 & 102 & 102 & 102 \\
\hline & SD & 1,11 & 1,04 & 0,99 & 0,79 \\
\hline \multirow[t]{3}{*}{ Afrikaans } & Mean & 5,39 & 4,82 & 5,25 & 5,15 \\
\hline & $\mathrm{N}$ & 96 & 96 & 96 & 96 \\
\hline & SD & 1,01 & 0,91 & 0,98 & 0,76 \\
\hline \multirow[t]{3}{*}{ Total } & Mean & 5,30 & 4,74 & 5,06 & 5,03 \\
\hline & $\mathrm{N}$ & 314 & 314 & 314 & 314 \\
\hline & SD & 1,10 & 1,04 & 1,02 & 0,82 \\
\hline
\end{tabular}

\section{Examining construct equivalence across language groups}

Factor analysis was conducted to examine the factor structure of the TCM Survey and the sub-scales and to compare the structure across language groups. For each subscale an unrotated single factor solution was obtained using the principal axis method for the pooled group and for each language group separately. The solution for each language group was then compared with the solution of the pooled group.

The coefficient of congruence for the language groups ranged from 0.90 to 0.99 , indicating that the factors of each group were similar to the factors of the pooled group. Table 2 summarises these results.

Overall, the coefficients of congruence were satisfactory and met the minimum requirement for construct equivalence (cf. MacCallum et al., 1999). Against this background, it was concluded that the TCM measured the same psychological constructs across the different language groups and that is was safe to draw comparisons of mean scores across the groups.

\section{Reliability}

The reliability of the TCM Survey was assessed by calculating Cronbach's co-efficient alpha for the entire organisational commitment scale and for the affective commitment, the continuance commitment and the normative commitment sub-scales within language groups. The reliability coefficients ranged from 0,56 to 0,83 as indicated in Table 3.

Whereas the reliabilities of the organisational commitment scale (pooled group, $\alpha=0,82$ ) and of the affective commitment sub-scale (pooled group, $\alpha=0,80$ ) were high across all three language groups, the reliabilities of the continuance commitment sub-scale (pooled group, $\alpha=0,62$ ) and normative commitment sub-scale (pooled group, $\alpha=$ $0,68)$ were unsatisfactory. Note that the reliabilities of the continuance commitment subscale for the Afrikaans language group $(\alpha=0,56)$ and the normative commitment subscale for the African language group $(\alpha=0,59)$ were clearly unsatisfactory.

\section{Comparing subscale correlations across language groups}

As a next step correlations between the three subscales were calculated independently for each language group. Using software developed by Silver, Zaikina, Hittner and May (2008), the equality of the correlations between the three subscales across the three language groups were tested by means of Paul's (1989) omnibus test for differences in independent correlations. No differences across language groups were observed for the correlations between (a) affective commitment and continuance commitment $\left(\chi^{2}=\right.$ 1,3824, $\mathrm{p}=0,501)$, (b) continuance commitment and normative commitment $\left(\chi^{2}=2,4098, p=0,230\right)$, and (c) affective commitment and normative commitment $\left(\chi^{2}=\right.$ $1,2335, \mathrm{p}=0,540)$. Against this background it appeared safe to conclude that the correlations are similar across language groups and that it is permissible to obtain the pooled correlations of the three variables: affective commitment and continuance commitment $(\mathrm{r}=0,362, \mathrm{p}<0,001)$, continuance commitment and normative commitment $(\mathrm{r}=$ $0,342, \mathrm{p}<0,001)$, and affective commitment and normative commitment $(\mathrm{r}=0,534, \mathrm{p}<0,001)$. 
Table 2: Coefficients of congruence across language groups

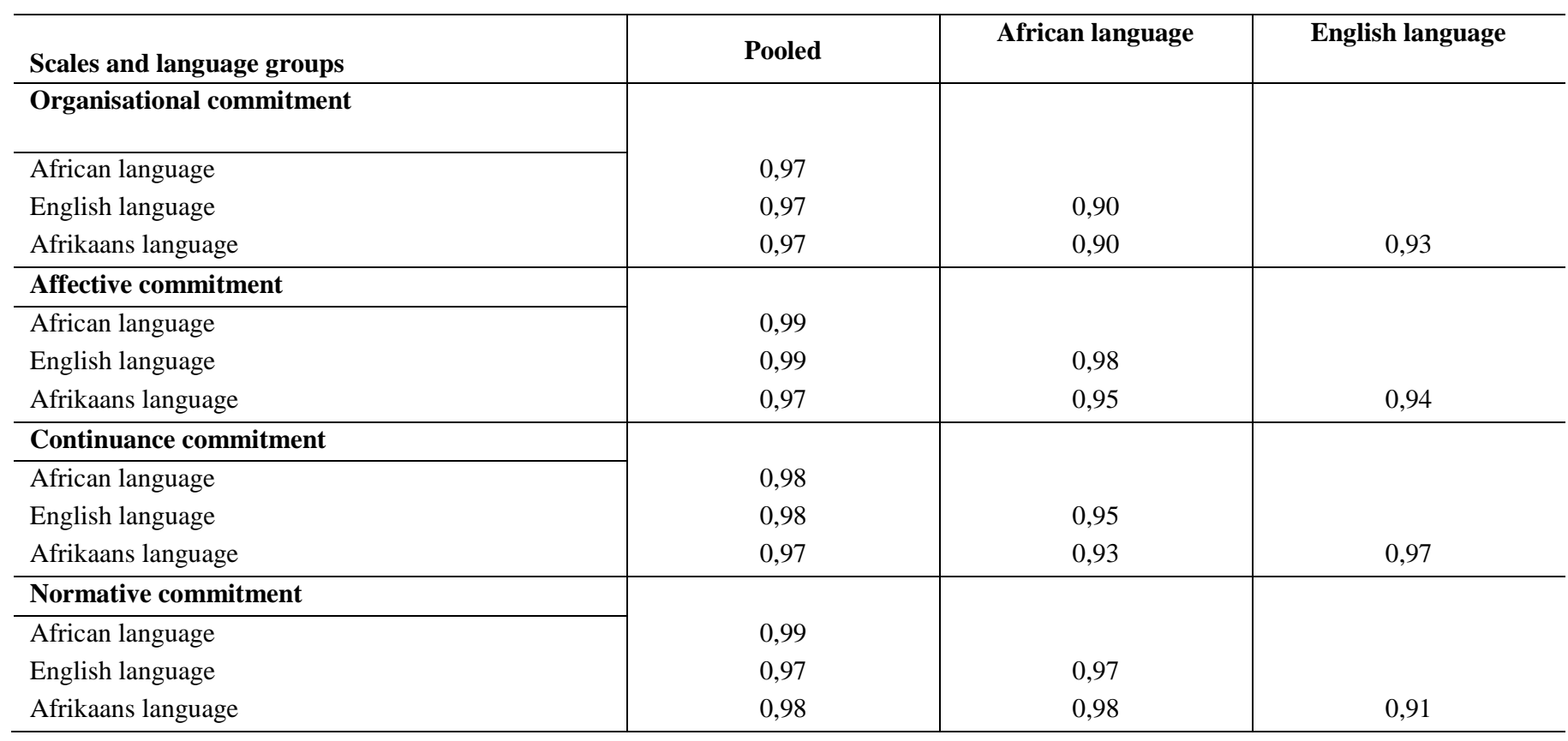

Table 3: Reliability coefficients for the TCM Survey

\begin{tabular}{l|c|c|c}
\hline \multicolumn{1}{c|}{ Scales } & Pooled & African language & English language \\
\hline Organisational commitment & 0,82 & 0,80 & \\
Affective commitment & 0,80 & 0,66 & 0,83 \\
Continuance commitment & 0,62 & 0,59 & 0,64 \\
Normative commitment & 0,68 & 0,78 & 0,70 \\
\hline
\end{tabular}

\section{Differential item functioning analysis}

In total 48 DIF tests were performed (24 of uniform DIF and 24 of non-uniform DIF). Two items displaying statistically significant uniform DIF was observed (items A1 and C4). For both of these items the uniform DIF accounted for less than $5 \%$ of the variance, indicating that the DIF was negligable from a practical perspective. There were also two items that displayed statistically significant non-uniform DIF (items C3 and N8). For both of these items, the nonuniform DIF appeared to be strong enough to take note of (for item C3 about 9\% of the variance; for item N8 about $6 \%$ of the variance), with the aim of revising them for future applications. However, within the context of the entire scale and its subscales it appears unlikely that the presence of the identified items would lead to noticeable biases in the estimation of mean scores. Against this background, the conditional ANOVA showed that, as a whole, the items of the three subscales functioned similarly across the three language groups.

\section{Comparing mean scores across the language groups}

Having established construct equivalence on the scale and item level, a multivariate analysis of variance (MANOVA) was performed with language group as the independent variable and affective commitment, continuance commitment and normative commitment as dependent variables. Wilk's lambda indicated a statistically significant relationship between language groups and the pooled set of dependent variables [Wilk's $\Lambda=0,937 ; F(6 ; 618)=3,401$; $p=0,003$.

A follow-up analysis of variance (ANOVA) was performed to determine for which of the components of organisational commitment the language groups differed significantly. Statistically significant differences in mean-scores of language groups were observed for normative commitment $\left[F(2 ; 311)=9,881 ; p<0,001 ;\right.$ partial $\left.\eta^{2}=0,060\right]$, but not for affective commitment $[F(2 ; 311)=1,652 ; p=0,193$; partial $\left.\eta^{2}=0,011\right]$ and continuance commitment $[F(2 ; 311)=$ 2,154; $p=0,118$; partial $\left.\eta^{2}=0,011\right]$.

Post-hoc Tukey's HSD tests were conducted to determine which language groups differed from one another on the normative-commitment scale. Tukey's HSD test indicated statistically significant differences between African language and English language respondents $(\mathrm{p}=0,001)$ and the African language and Afrikaans language respondents ( $\mathrm{p}$ $=0,001$ ), but not between English language and Afrikaans language respondents $(\mathrm{p}=0,992)$. The findings indicated that the English language group (mean score $=5,25$ ) and the Afrikaans language group (mean score $=5,24$ ) scored significantly higher on normative commitment than the African language group (mean score $=4,73$ ). 


\section{Discussion}

The aim of this study was to gain a better understanding of cross-cultural similarities and differences in organisational commitment in the South African automotive industry. To this end the study focused on two aspects, namely (a) the psychological and measurement equivalence of the commitment construct across three different language groups, and (b) conditional on the demonstration of equivalence, the comparison of mean scores for affective commitment, normative commitment, and continuance commitment across the three groups.

The factor analyses of the TCM Survey, the comparison of the subscale correlations across the African, English and Afrikaans language groups, and the DIF analysis support the view that the organisational commitment construct is psychologically equivalent across the language groups. The results provide support for the construct validity of the scale and its subscales. The results are also broadly supportive of the measurement equivalence of the TCM Survey across the three groups, but the results also indicate that a small number of items may need to be revised to move closer to the ideal of having a scale that functions exactly the same across different language groups (and by implication different cultural groups) in South Africa. In addition, the reliabilities of the subscales are not entirely satisfactory and need to be improved if the TCM Survey is to represent a major operationalisation of the organisational commitment construct in the South African context. The best way to achieve this aim might be to write additional items for each of the subscales. Overall, however, the observed structural and measurement equivalence of the construct implies that managers may move towards a universal description and definition of organisational commitment in South Africa and that the TCM Survey holds promise as a measure of the construct in the multicultural South African context.

With respect to the different language groups' mean scores, statistically significant mean differences were observed for the multivariate combination of affective commitment, continuance commitment and normative commitment. Against this background, the null hypothesis of no mean differences between the three language groups is rejected. Follow-up analyses indicated that (a) for affective commitment and continuance commitment, no statistically significant mean score differences across the three language groups were observed; and (b) for normative commitment, African language respondents scored significantly lower than English language and Afrikaans language respondents.

The findings of this study that appear to suggest that African language employees have lower normative commitment (i.e. they feel less obliged to stay with the organisation), alerts one to the possibility of higher turnover of African employees (Foote, Seipel, Johnson \& Duffy, 2005; Stallworth, 2003; 2004). This may have management implications in contemporary South Africa, where it is highly desirable to attract and retain African employees in the workplace in terms of responding to the demands of the Employment Equity Act (Republic of South Africa, 1998) and the potential that a diverse employee body brings to the competitive advantage of companies (Karma \& Vedina, 2009).

It is important to interrogate the reasons for the lower normative commitment of the African language respondents. Three possible interpretations are offered here. Firstly, the requirements of the Employment Equity Act (Republic of South Africa, 1998), which dictate that companies must employ people from previously disadvantaged groups against a targeted plan, has resulted in fierce competition for scarce skills among skilled African employees (Kraak, 2008). This has created a situation where the demand for talented African employees often exceeds the supply of such candidates. In turn, this may have resulted in greater job opportunities for talented African employees in comparison to their white counterparts who could potentially negatively impact the normative commitment of African employees, or the feeling of obligation to stay in current employment, even in an economic downturn. A second interpretation is that African respondents may feel isolated in exclusionary organisational cultures (Thomas, 2002), which may lead to lowered affective commitment, which in turn might lead to a decreased obligation (i.e. lower normative commitment) to stay in the organisation when other job opportunities arise. The literature suggests that there is a link between normative commitment and affective commitment (cf. Martin, 2008), such that a decrease in affective commitment is associated with a decrease in normative commitment. In accordance with the literature, a moderately strong positive correlation between affective and normative commitment was observed in the present study. A third but related interpretation could suggest that there is a lack of fit between the goals and values of African language employees and the goals and values of the organisation (cf. Alatrista \& Arrowsmith, 2004; Etzioni. 1964). Historically in South Africa, organisations have been driven by Eurocentric goals and values that may not fit well with the goals and values associated with an African worldview (Lessem et al., 1993). Such dissonance may lead to decreased normative commitment (Alatrista \& Arrowsmith, 2004; Kirby \& Richard, 2000) on the part of African language speakers.

\section{Limitations of the study}

Inherent in the present study are the following limitations:

1. While the factor analyses indicated that the TCM measured similar constructs across the three language groups, it is possible that the meaning of the constructs in South Africa might differ from that in North America (where the instrument was developed). Note that the reliabilities of some subscales - noticeably continuance commitment for the Afrikaans group and normative commitment for the African group - were disappointingly low for some groups. This finding indicates that more work on the psychometric properties of the TCM in South Africa is required.

2. Each of the three broad language groups were treated as though they represent homogeneous categories. Yet, 
within each of the language groups it is possible to draw distinctions between various subgroups. The small number of coloured $(2,2 \%)$ and Indian respondents $(4,2 \%)$ may have been included within the broad English and Afrikaans language groups according to their self-reported first language. It is possible that these respondents do not endorse the worldview of the English and Afrikaans language groups. However, given that these respondents comprised a small number, it is not expected that this factor significantly influenced findings. Similarly, within the broad African language group, various subgroups can be expected to exist. Hence, the present study may have overlooked nuances that could exist within the broad language group categories. The broad language groups did not contain sufficient numbers of respondents to sustain finer segmentation according to subgroups, which could be the topic of a future study.

3. The study is based on the responses of employees of one organisation in a specific industry. It is not clear that the findings can be generalised to other settings. However, generalisability may not necessarily be compromised by non-random sampling if there is a well-defined population (Highhouse \& Gillespie, 2009), which in the case of the present study is the automotive industry. It appears reasonable to suggest that the findings could provide management insights within the broader automotive industry in South Africa. In this respect there appears to be no apriori reason to expect that the differences observed between Afrikaans and English employees on the one hand, and African language speaking workers on the other hand, would differ across organisations.

4. Questionnaires were distributed and collected by regional human resources managers, which may have unwittingly caused respondents to doubt assurances of the anonymity of their responses. Accordingly, responses may have been "sensitive to unintended influences" (Leedy \& Ormrod, 2005:208) and some distortion may exist. However, these influences would be expected to apply equally across the three groups.

\section{Conclusion}

Organisational commitment research in South Africa is limited and the challenges of proactively meeting the sentiments of employment equity and organisational competitiveness are unlikely to be achieved unless organisations have a cadre of committed employees (Winter \& Jackson, 2006). This study has achieved its overall purpose of deepening the understanding of organisational commitment amongst different cultural groups in the automotive industry and the findings suggest that culture matters.

Given that human capital is a driver of organisational competitiveness (Nijhof et al., 1998), the finding that African language respondents display lower normative commitment than do their English and Afrikaans speaking counterparts is potentially important for management in this strategic South African industry. Needing to attract, develop and retain talented African employees, who together with their white counterparts can create workplace diversity that can be used for competitive advantage (McFarlin \& Sweeny, 1992; Du Plessis, 2007; Nel \& du Plessis, 2007; Karma \& Vedina, 2009), organisations should monitor levels of commitment and develop strategies that foster loyalty and feelings of obligation to remain in the organisation. Loo (1999: 321) suggests that, within the context of cultural diversity in the workplace, managers need to embark upon a "critical reflective learning approach" which includes, according to Tjosvold and Leung (2003), appreciating the limitations of traditional organisational theories and management approaches that assume cultural homogeneity.

Against the background aims of the Employment Equity Act (Republic of South Africa, 1998), the findings of the present study provide a challenge to management to better understand the reasons for the lower normative commitment of African employees than that of English and Afrikaans speaking employees and, accordingly, to devise strategies for improving normative commitment within this group. This is a potentially rich area for further research along with a deep exploration of the drivers of normative commitment amongst more refined cultural subgroups.

\section{References}

Alatrista, J. \& Arrowsmith, J. 2004. 'Managing employee commitment in the not-for-profit sector', Personnel Review, 33(5): 536-548.

Allen, N.J. \& Meyer, J.P. 1990. 'The measurement and antecedents of affective, continuance and normative commitment to the organization', Journal of Occupational Psychology, 63: 1-18.

Appelbaum, S.H., Shapiro, B. \& Elbaz, D. 1998. 'The management of multicultural group conflict', Team Performance Management, 4(5): 211-234.

Bangeni, B. \& Kapp, R. 2007. 'Shifting language attitudes in a linguistically diverse learning environment in South Africa', Journal of Multilingual and Multicultural Development, 28: 253-269.

Bassett-Jones, N. \& Lloyd, G. 2005. 'The paradox of diversity management', Journal of Creativity and Innovation Management, 14(2): 169-175.

Batra, G.S. 1996. 'Human resource auditing as a tool of human resource valuation: Interface and emerging practices', Managerial Auditing Journal, 11(8): 23-30.

Berndt, A. \& Herbst, F. 2006. 'Service quality in the motor vehicle industry in South Africa: An exploratory study', Southern African Business Review, 10(2): 97-110.

Bhadury, J., Mighty, E.J. \& Damar, H. 2000. 'Maximizing workforce diversity in project teams: A network flow approach', Omega, 28: 143-153. 
Bishop, J.M. 1997. 'How commitment affects team performance: Employee commitment', HR Magazine, February: 1-5.

Chattopadhyay, P. 1999. 'Beyond direct and symmetrical effects. The influence of demographic dissimilarity on organizational citizenship behaviour', Academy of Management Journal, 42: 273-287.

Cox, T.H. \& Blake, S. 1991. 'Managing cultural diversity: implications for organizational competitiveness', Academy of Management Executive, 5(3): 45-56.

De Chernatony, L. \& Segal-Horn, S. 2003. 'The criteria for successful services brands', European Journal of Marketing, 37(7-8): 1095-1118.

Demer, J. 2002. 'Crossing the cultural divides', CMA Management, September: 28-30.

Du Plessis, A.J. 2007. 'Change, organisational development and culture: Human resource management's role in a future South Africa', International Review of Business Research Papers, 3(1): 1-10.

Erwee, R., Lynch, B., Millett, B., Smith, D. \& Roodt, G. 2001. 'Cross-cultural equivalence of the organisational culture survey in Australia', Journal of Industrial Psychology, 27(3): 7-12.

Etzioni, A. 1964. Modern organizations. Englewood Cliffs, NJ: Prentice-Hall.

Evans, D. 2006. 'Creating value from cross-cultural teams: An example of Franco-British collaborative ventures', Cross-Cultural Management: An International Journal, 13(4): 316-329.

Fontaine, R. 2007. 'Cross-cultural management: Six perspectives', Cross Cultural Management: An International Journal, 14(2): 125-135.

Foote, D.A., Seipel, S.J., Johnson, N.B. \& Duffy, M.K. 2005. 'Employee commitment and organizational policies', Management Decision, 13(2): 203-219.

Gellatly, I.R. 1995. 'Individual and group determinants of employee absenteeism: Test of a causal model', Journal of Organizational Behavior, 16(5): 469-485.

Higgs, M. 1996. 'Overcoming the problems of cultural differences to establish success for international management teams', Team Performance Management: An International Journal, 2(1): 36-43.

Highhouse, S. \& Gillespie, J.Z. 2009. 'Do samples really matter that much?' In Lance, C.E. \& Vandenburg, R.J. (Eds.) Statistical and methodological myths and urban legends: Doctrine, verity and fable in the organizational and social sciences. New York: Routledge.
Hofstede, G. 2001. Culture's consequences: Comparing values, behaviors, institutions, and organizations across nations. New York: Sage.

Horn, G.S. 2007. 'Black economic empowerment in the Eastern Cape automotive industry: Challenges and policies', South African Journal of Economic and Management Sciences, 10(4): 490-503.

House, R.J., Hanges, P.J., Javidan, M., Dorfman, P.W. \& Gupta, V. 2004. Leadership, culture, and organizations: The GLOBE study of 62 societies. Thousand Oaks, CA: Sage Publications.

Jackson, P.R. 2004. 'Employee commitment to quality: Its conceptualisation and measurement', International Journal of Quality and Reliability Management, 21(7): 714-730.

Jackson, T. 2002. International HRM: A cross-cultural approach. London: Sage Publications.

Kamenou, N. \& Fearfull, A. 2006. 'Ethnic minority women: A lost voice in HRM', Human Resource Management Journal, 16(2): 154-172.

Kanter, R.M. \& Corn, R.I. 1994. 'Do cultural differences make a business different? Contextual factors affecting cross-cultural relationship success', Journal of Management Development, 13(2): 5-23.

Karma, K. \& Vedina, R. 2009. 'Cultural intelligence as a prism between workforce diversity and performance in a modern organization', Review of International Comparative Management, 10(3): 527-542.

Kazlauskaite, R., Buciuniene, I. \& Turauskas, L. 2006. 'Building employee commitment in the hospitality industry', Baltic Journal of Management, 1(3): 300-314.

Kirby, S.L. \& Richard, O.C. 2000. 'Impact of marketing work-place diversity on employee job involvement and organizational commitment', The Journal of Social Psychology, 140(3): 367-377.

Kraak, A. 2008. 'Incoherence in the South African labour market for intermediate skills', Journal of Education and Work, 21(3): 197-215.

Labatmediené, L., Endriulaitiené, A.E. \& Gustainiené, L.G. 2007. 'Individual correlates of organizational commitment and intention to leave the organization', Baltic Journal of Management, 2(2): 196-212.

Lee, K., Allen, N.J., Meyer, J.P. \& Rhee, K.Y. 2001. 'Three-component model of organizational commitment: An application to South Korea', Applied Psychology: An International Review, 50(4): 596-614.

Leedy, P.D. \& Ormrod, J.E. 2005. Practical research: Planning and design. $8^{\text {th }}$ Edition. Upper Saddle River, NJ: Prentice Hall. 
Lessem, R., Christie, P. \& Mbigi, L. 1993. African management: philosophies, concepts and applications. Randburg: Knowledge Resources.

Loo, R. 1999. 'A structured exercise for stimulating crosscultural sensitivity', Career Development International, 4(6): 321-324.

Lytle, R.S. \& Timmerman, J.E. 2006. 'Service orientation and performance: An organizational perspective', Journal of Services Marketing, 20(2): 136-147.

MacCallum, R.C., Widaman, K.F., Zhang, S. \& Hong, S. 1999. 'Sample size in factor analysis', Psychological Methods, 4(1): 84-99.

Markus, H. \& Kitayama, S. 1991. 'Culture and the self: Implications for cognition, emotion, and motivation', Psychological Review, 98: 224-253.

Martin, S.S. 2008. 'Relational and economic antecedents of organisational commitment', Personnel Review, 37(6): 589608.

Martins, S. 2006. 'Detecting sub-cultures in an organisation', Southern African Business Review, 10(2): 130-149.

Mathieu, J.E. \& Zajac, D.M. 1990. 'A review and metaanalysis of the antecedents, correlates, and consequences of organizational commitment', Psychological Bulletin, 108(2): 171-194.

Mbigi, L. 1997. The African dream in management. Randburg: Knowledge Resources.

McClean, M. 2000. 'Student associations at a South African medical school: Implications for educators', Teaching in Higher Education, 5: 323-344.

McFarlin, D.B. \& Sweeny, P.D. 1992. 'Distributive and procedural justice as predictors of satisfaction with personal and organizational outcomes', Academy of Management Journal, 35: 626-637.

Mellahi, K. 2001. 'Differences and similarities in future managerial values: A five cultures comparative study', Cross Cultural Management, 8(1): 45-53.

Meyer, J.P. \& Allen, N.J. 1991. 'A three-component conceptualization of organizational commitment', Human Resource Management Review, 1(1): 61-89.

Meyer, J.P. \& Herscovitch, L. 2001. 'Commitment in the workplace: Toward a general model', Human Resources Management Review, 11: 299-326.

Miller, K., Haskell, C. \& Thatcher, A. 2002. 'The relationship between intention to emigrate and organisational commitment', South African Journal of Psychology, 32(3): 16-20.
Moorman, R.H., Niehoff, B.P. \& Organ, D.W. 1993. 'Treating employees fairly and organizational citizenship behaviour: Sorting the effects of job satisfaction, organizational commitment, and procedural justice', Employee Responsibilities and Rights Journal, 6(3): 209225.

Mowday, R.T., Steers, R.M. \& Porter, L.W. 1979. 'The measurement of organisational commitment', Journal of Vocational Behavior, 14: 224-247.

Naudé, P., Desai, J. \& Murphy, J. 2003. 'Identifying the determinants of internal marketing orientation', European Journal of Marketing, 37(9): 1205-1220.

Nel, P.S. \& Du Plessis, A.J. 2007. 'HR and management challenges for South Africa in the context of workplace diversity', International Review of Business Research Papers, 3(5): 308-327.

Ng, S.W.E. \& Burke, R.F. 2004. 'Cultural values as predictor of attitudes towards equality and diversity', Women in Management Review, 19(6): 317-324.

Nijhof, W.J., De Jong, M.J., \& Beukhof, G. 1998. 'Employee commitment in changing organisations: An exploration', Journal of European Industrial Training, 22(6): 243-248.

Paul, S.R. 1989. 'Test for the equality of several correlation coefficients', The Canadian Journal of Statistics, 17: 217227.

Peppas, S.C. \& Yu, T.T. 2007. 'A cross-cultural assessment of attitudes of business students toward business ethics', Chinese Management Studies, 1(4): 243-256.

Pretorius, B. 2006. 'This is our business'. Inhouse document of McCarthy Limited. Johannesburg.

Rashid, M.Z.A., Sambasivan, M. \& Johari, J. 2003. 'The influence of corporate culture and organisational commitment on performance', Journal of Management Development, 22(8): 708-728.

Republic of South Africa. 1998. Employment Equity Act, No. 55. Gazette No.19370. Pretoria: The Government Printer.

Richard, O.C. 2000. 'Racial diversity, business strategy, and firm performance: A resource-based view', Academy of Management Journal, 43(2): 164-177.

Riordan, C.M. \& Shore, L.M. 1997. 'Demographic diversity and employee attitudes: An empirical examination of relational demography within work units', Journal of Applied Psychology, 83(3): 342-358.

Robbins, S.P. \& Judge, T.A. 2007. Organizational behavior. $12^{\text {th }}$ Edition. Upper Saddle River, NJ: Prentice Hall.

Rudman, E. 2008. 'Conversations', People Dynamics, 26(8): 12-14. 
Rudwick, S. 2008. "“Coconuts" and "oreos": Englishspeaking Zulu people in a South African township', World Englishes, 27: 101-116.

Rupert, J., Jehn, K.A., Van Engen, M.L. \& De Reuver, R.S.M. 2010. 'Commitment of cultural minorities in organizations: Effects of leadership and pressure to conform', Journal of Business Psychology, 25(1): 25-37.

Seymen, O.A. 2006. 'The cultural diversity phenomenon in organisations and different approaches for effective cultural diversity management: A literary review', Cross Cultural Management: An International Journal, 13(4): 296-315.

Shepherd, J.L. \& Mathews, B.P. 2000. 'Employee commitment: Academic and practitioner perspective', Employee Relations, 22(6): 555-575.

Silver, N.C., Zaikina, H., Hittner, J.B. \& May, K. 2008. 'INCOR: A computer program for testing differences among independent correlations', Molecular Ecology Resources, 8: 763-764.

Somers, M.J. 1995. 'Organizational commitment, turnover and absenteeism: An examination of direct and interaction effects', Journal of Organizational Behavior, 16(1): 49-58.

Song, J.H. \& Kim, H.M. 2009. 'The integrative structure of employee commitment: The influential relations of individuals' characteristics in a supportive learning culture', Leadership and Organization Development Journal, 30(3): 240-255.

Stallworth, L. 2003. 'Mentoring, organizational commitment and intention to leave public accounting', Managerial Auditing Journal, 18(5): 405-418.

Stallworth, L. 2004. 'Antecedents and consequences of organizational commitment to accounting organizations', Managerial Auditing Journal, 19(7): 945-955.

Tam, Y.M., Korczynski, M. \& Frenkel, S.J. 2002. 'Organizational and occupational commitment: Knowledge workers in large corporations', Journal of Management Studies, 39(6): 776-801.

Tan, J.A.C., Härtel C.E.J., Panipucci, D. \& Strybosch, V.E. 2005. 'The effects of emotions in cross-cultural expatriate experiences', Cross Cultural Management, 12(2): 4-15.

Thomas, A. 2002. 'Employment equity in South Africa: Lessons from the global school', International Journal of Manpower, 23(3): 237-255.

Thomas, A. 2003. 'Employment equity at selected companies in South Africa', South African Journal of Labour Relations, 27(3-4): 6-41.

Thomas, D.A. \& Ely, R.J. 1996. 'Making differences matter: A new paradigm for managing diversity', Harvard Business Review, 74(5): 79-90.
Tjosvold, D. \& Leung, K. 2003. 'Cross-cultural foundations: Traditions for managing in a global world'. In Tjosvold, D. \& Leung, K. (Eds) Cross-cultural management: Foundations and futures. Aldershot, Hants: Ashgate Publishing Limited.

Triandis, H.C. 2001. 'Individualism and collectivism: Past, present and future'. In Matsumoto, D. (Ed.). The handbook of culture and psychology. Oxford: Oxford University Press.

Van de Vijver, F. \& Leung, K. 1997. Methods and data analysis for cross-cultural research. Thousand Oaks, California: Sage Publications.

Van de Vijver, F. \& Tanzer, N.K. 2004. 'Bias and equivalence in cross-cultural assessment: An overview', Revue Européenne de Psychologie Appliquée, 54: 119-135.

Welkenhuysen-Gybels, J.G.J. \& Van de Vijver, F.J.R. 2001. 'A comparison of methods for the evaluation of constructequivalence in a multi-group setting', Proceedings of the annual meeting of the American Statistical Association, August: 5-9. Amsterdam: American Statistical Association.

Williamson, I.O., Burnett, M.F. \& Bartol, K.M. 2009. 'The interactive effect of collectivism and organizational rewards on affective organizational commitment', Cross Cultural Management: An International Journal, 16(1): 28-43.

Winter, R. \& Jackson, B. 2006. 'State of the psychological contract: Manager and employee perspectives within an Australian credit union', Employee Relations, 28(5): 421434. 